\title{
PERAN MARKET VALUE ADDED DALAM MEMODERASI PENGARUH PENGUNGKAPAN CORPORATE SOCIAL RESPONSIBILITY TERHADAP NILAI PERUSAHAAN
}

\begin{abstract}
This research aims to determine whether the disclosure of CSR affects the company value. This study also uses Market Value Added (MVA) as a moderating variable to determine whether MVA can strengthen or weaken the relationship between CSR and company value by applying Moderate Regression Analysis (MRA) as the analytical method. Three companies are selected as the samples of transport and infrastructure sector listed in the Indonesia Stock Exchange within 2011-2015. The samples are Samudera Indonesia, Mitra International Resources, and Garuda Indonesia. The result of this research indicates that the disclosure of CSR does not have significant affects to the corporate value with the acquisition of $R$ square $1.3 \%$ of which the remaining $98.7 \%$ is influenced by other variables. This study also states that the Market Value Added (MVA) is not able to moderate the relation between CSR with the company value which means that CSR cannot increase the value of the company at the time when MVA is high.
\end{abstract}

ABSTRAK: Penelitian ini bertujuan untuk mengetahui pengaruh pengungkapan CSR dengan nilai perusahaan menggunakan metode analisis regresi sederhana. Selain itu dalam penelitian ini juga menggunakan Market Value Added (MVA) sebagai variabel moderasi untuk mengetahui apakah MVA dapat memperkuat atau memperlemah hubungan antara CSR dengan nilai perusahaan dengan menggunakan metode analisis Moderate Regression Analysis (MRA). Pada penelitian ini terdapat tiga sampel perusahaan sektor transportasi dan infrastruktur yang terdaftar di Bursa Efek Indonesia tahun 2011 sampai dengan 2015, yaitu Samudera Indonesia, Mitra International Resources, dan Garuda Indonesia. Hasil penelitian ini menunjukan bahwa pengungkapan CSR tidak berpengaruh signifikan terhadap nilai perusahaan dengan nilai signifikasi sebesar 0,681 dan perolehan $\mathrm{R}$ square sebesar 0.013 atau $1.3 \%$ yang mana sisanya yaitu $98.7 \%$ dipengaruhi oleh variabel lain. Di samping itu, penelitian ini juga menyatakan bahwa Market Value Added (MVA) tidak berhasil memoderasi hubungan antara pengungkapan CSR dengan nilai perusahaan, artinya pengungkapan CSR tidak dapat meningkatkan nilai perusahaan pada saat MVA perusahaan tinggi dan sebaliknya.

\author{
Astrie Krisnawati ${ }^{1}$, Sarah \\ Khaerunnisha Fathiarani ${ }^{2}$ \\ ${ }^{1,2}$ Fakultas Ekonomi \& Bisnis, \\ Universitas Telkom \\ Jl. Telekomunikasi No.1, \\ Bandung, Indonesia
}

Keywords: Corporate Social Responsibility, Market Value Added, Company Value

Kata Kunci: Corporate Social Responsibility, Market Value Added, Nilai Perusahaan 


\section{Pendahuluan}

Istilah Corporate Social Responsibility (CSR) kini sudah tidak asing lagi di kalangan masyarakat dan pelaku bisnis. Pelaksanaan CSR menjadi salah satu fokus utama karena masyarakat saat ini mulai peduli terhadap pelaksanaan CSR akibat meningkatnya kerusakan lingkungan. Kepedulian masyarakat terhadap CSR seakan-akan merupakan celah bagi perusahaan untuk menerapkan CSR dengan tujuan agar perusahaan memiliki citra baik di mata masyarakat dan akhirnya akan berdampak positif bagi perusahaan berupa penjualan produk atau jasa yang akan meningkat.

Mulanya paradigma strategi bisnis hanya single bottom line yang direfleksikan dari kondisi keuangan dan aspek ekonomi, sekarang menuju pada triple bottom line yaitu keuangan, sosial, dan lingkungan. Konsep tersebut mengakui bahwa jika perusahaan ingin sustain, maka perlu memperhatikan $3 \mathrm{P}$ yaitu bukan hanya profit yang diburu, namun juga harus memberikan kontribusi positif kepada masyarakat (people), dan ikut aktif dalam menjaga elestarian lingkungan (planet) (Elkington, 1997). Konsep triple bottom line tersebut merupakan kelanjutan dari konsep sustainable development yang secara eksplisit telah mengaitkan antara dimensi tujuan dan tanggungjawab, baik kepada shareholder maupun stakeholder (Hadi, 2011:56).

$$
\text { Pelaksanaan CSR juga }
$$

mengakomodir kewajiban yang diadakan pemerintah kepada perusahaan yang kegiatan usahanya di bidang dan/atau berkaitan dengan sumber daya alam melalui Undang-Undang Nomor 40 Tahun 2007 tentang Perseroan Terbatas Pasal 74 ayat (1) menyatakan "Perseroan yang menjalankan kegiatan usahanya di bidang dan/atau berkaitan dengan sumber daya alam, wajib melaksanakan Tanggung Jawab Sosial dan Lingkungan”.
Namun yang tidak berkaitan langsung dengan sumber daya alam terdapat pada Undang-Undang Penanaman Modal No.25 Tahun 2007 Pasal 15 yang berisi "Setiap penanaman modal berkewajiban melaksanakan tanggung jawab social perusahaan", dan dalam Peraturan Menteri BUMN No.9 Tahun 2015 yang menyatakan "Perum dan Persero wajib melaksanakan Program Kemitraan dan Program BL".

Persaingan yang ketat ini justru membuat perusahaan hanya fokus kepada kepentingan shareholder, yang secara langsung dianggap dapat memberikan kontribusi pada perusahaan yaitu melalui pengikutsertaan modal, dan mulai mengabaikan kepentingan stakeholder, dengan menganggap bahwa mereka tidak memberi kontribusi langsung pada perusahaan (Freeman, 1984). Hal ini sesuai dengan teori legitimasi yang dinyatakan oleh Harsanti (2011) bahwa setiap perusahaan memiliki kontrak dengan masyarakat berdasarkan nilai-nilai keadilan dan bagaimana perusahaan menanggapi berbagai kelompok melegitimasi tindakan perusahaan. Jika terjadi perselisihan atau ketidakselarasan antara perusahaan dengan masyarakat, maka perusahaan akan kehilangan legitimasinya dan posisi perusahaan akan terancam. Berikut ini beberapa permasalahan sosial yang terjadi pada dunia bisnis di Indonesia akibat ketidakselarasan perusahaan dengan stakeholder.

$$
\text { Berdasarkan yang telah }
$$

dikemukakan oleh Badan Pusat Statistik, pertumbuhan ekonomi Indonesia terus menurun sejak tahun 2011 hingga tahun 2015. Pada tahun 2011 angka pertumbuhan ekonomi Indonesia menyentuh hingga $6,44 \%$ yang terus menerus diikuti oleh penurunan hingga tahun 2015 menjadi 4,79\%. Pemerintah yang secara terus menerus menargetkan angka pertumbuhan ekonomi Indonesia untuk terus meningkat namun tidak 
terealisasikan. Wakil Menteri Perhubungan Republik Indonesia, Bambang Susantono, Ph. D, mengungkapkan bahwa berdasarkan perolehan data dari Badan Pusat Statistik diketahui pertumbuhan sektor transportasi terus mengalami pertumbuhan. Pada tahun 2011 pertumbuhan PDB transportasi sebesar 9\%, 2012 sebesar 9,6\%. 2013 sebesar $10.05 \%$, dan tahun 2014 mencapai 10,5\%. Dengan demikian, diketahui kontribusi sektor transportasi terhadap PDB Nasional terus ikut meningkat, dimana pada tahun 2011 sebesar 3,97\%, tahun 2012 sebesar 4,09\%, tahun 2013 sebesar $4,22 \%$, dan pada tahun 2014 sebesar 4,36\%.

\begin{tabular}{lcr}
\multicolumn{1}{c}{ Besarnya } & kontribusi sektor \\
transportasi & menandakan bahwa \\
perusahaan & sektor transportasi kian \\
berkembang & dan mengalami \\
pertumbuhan. & Perkembangan dan
\end{tabular}
pertumbuhan sektor transportasi yang baik tersebut akan dapat memberikan manfaat yang lebih besar bagi kesejahteraan nasional apabila perusahaan-perusahaan yang berada pada sektor transportasi mematuhi kewajibannya untuk menjalankan CSR.

Pengungkapan $C S R$ yang dilakukan oleh perusahaan itu sangat penting agar dapat diketahui oleh para stakeholder. Pengungkapan CSR dipercaya dapat meningkatkan nilai perusahaan, pengungkapan $C S R$ juga bertujuan untuk memperlihatkan aktivitas sosial yang telah dilakukan oleh perusahaan dan pengaruhnya bagi masyarakat (Harsanti, 2011).

Berdasarkan yang telah dikemukakan Eforis dan Suryaningsih (2011), dampak dari pelaksanaan CSR terhadap nilai perusahaan dapat dilihat dari meningkatnya penjualan produk barang atau jasa perusahaan karena bagi konsumen produk yang mereka konsumsi memiliki nilai tambah dan mereka akan merasa memiliki sumbangsih secara tidak langsung terhadap kegiatan sosial perusahaan, sehingga reputasi perusahaan akan semakin meningkat di mata para stakeholder-nya terkait pelaksanaan CSR. Dan untuk menunjang variabel moderasi yaitu value added terhadap nilai perusahaan, berikut merupakan daftar tabel harga saham objek perusahaan yang digunakan dalam penelitian ini.

\section{Tabel 1. Harga Saham Penutupan Objek Penelitian}

\begin{tabular}{|c|l|l|l|l|l|l|}
\hline No. & Perusahaan & $\mathbf{2 0 1 1}$ & $\mathbf{2 0 1 2}$ & $\mathbf{2 0 1 3}$ & $\mathbf{2 0 1 4}$ & $\mathbf{2 0 1 5}$ \\
\hline 1 & SMDR & 3700 & 4025 & 2900 & 4850 & 5050 \\
\hline 2 & MIRA & 160 & 123 & 58 & 50 & 50 \\
\hline 3 & GIAA & 475 & 660 & 500 & 555 & 309 \\
\hline
\end{tabular}

Berdasarkan tabel di atas, diketahui data harga saham penutupan dari ketiga perusahaan pada tahun 2011 hingga tahun 2015. Pada perusahaan SMDR dan GIAA harga saham cenderung fluktuatif, dapat dilihat pada SMDR tahun 2013 mengalami penurunan menjadi Rp. 2.900,- kemudian harga saham kembali naik hingga pada tahun 2015 menjadi Rp. 5.050,-. Begitu pun dengan GIAA, mengalami peningkatan dan penurunan harga saham setiap tahunnya, hingga pada tahun 2015 harga saham GIAA sebesar Rp. 309,-. Hal berbeda terjadi pada perusahaan MIRA yang cenderung menurun setiap tahunnya hingga pada tahun 2015 harga saham perusahaannya hanya Rp. 50-. Sedangkan ditinjau dari laba bersihnya (dalam juta rupiah). Digunakan komponen tersebut karena harga saham merupakan komponen yang dibutuhkan dalam perhitungan nilai perusahaan dan Market Value Added (MVA). Nilai perusahaan dalam penelitian ini diwakili oleh nilai Tobin's Q.

$$
\text { Manfaat peningkatan nilai }
$$
perusahaan apabila dilihat dari sudut pandang manajemen perusahaan ialah meningkatnya investasi yang ditanamkan ke perusahaan karena investor lebih memiliki kepercayaan terhadap manajemen perusahaan. Kesejahteraan karyawan juga akan bertambah karena perusahaan tidak hanya berfokus pada penjualan namun juga 
memperhatikan pihak-pihak yang terlibat di dalam aktivitas perusahaan. Peningkatan nilai perusahaan juga diapresiasi pihak eksternal yakni pihak investor dan pihak kreditor. Bagi investor, perusahaan yang memiliki EVA atau MVA yang besar dapat memberikan capital gain atau pembagian dividen atas modal yang telah ditanamkan ke perusahaan. Bagi kreditor perusahaan dipandang memiliki kemampuan untuk mengembalikan pinjaman sesuai jumlah dan waktu pembayaran yang telah disepakati (Eforis dan Suryaningsih, 2011).

MVA merupakan seberapa besar kekayaan yang dihasilkan perusahaan untuk memaksimalkan kesejahteraan para pemegang saham. MVA dipilih sebagai variabel moderasi karena merupakan pengukuran kinerja keuangan secara eksternal yaitu mengukur efek dari tindakan manajerial dari sejak awal perusahaan didirikan yang bertujuan untuk mensejahterakan para pemegang saham dengan memaksimalkan selisih antara nilai pasar ekuitas dan modal yang ditanamkan investor pada perusahaan. Dengan menggunakan metode tersebut dapat diketahui apakah manajer berhasil menciptakan nilai tambah bagi perusahaan atau justru gagal dalam menciptakan nilai tambah bagi perusahaan.

\section{Pengembangan Hipotesis}

Berdasarkan teori-teori dan penelitianpenelitian terdahulu yang relevan, dapat digambarkan kerangka pemikiran sebagai berikut:

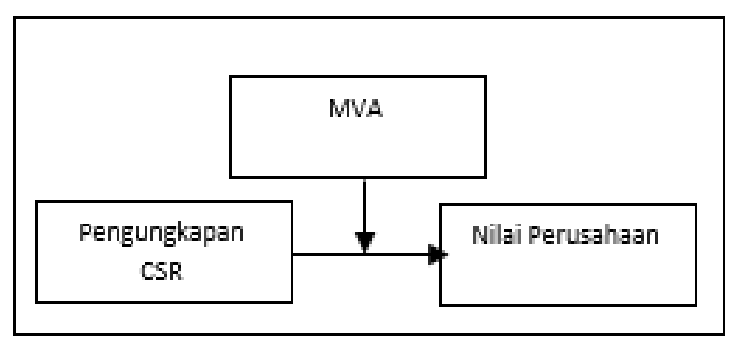

Gambar 1. Kerangka Pemikiran
Berdasarkan kerangka pemikiran pada Gambar 2, maka dapat dirumuskan hipotesis penelitian sebagai berikut.

H1: Pengungkapan Corporate Social Responsibility berpengaruh signifikan terhadap nilai perusahaan.

H2: MVA mampu memoderasi hubungan pengungkapan CSR dengan nilai perusahaan.

\section{Metode, Data dan Analisis}

Pada penelitian ini terdapat Variabel Independen atau variabel bebas merupakan varibel yang memengaruhi variabel lain (Sarwono, 2013:62). Dalam penelitian ini, penulis menggunakan Corporate Social Responsibility Diclosure Index sebagai variabel bebas (independen) yang di proksikan dengan perhitungan Global Reporting Innitiative (GRI). Variabel Dependen adalah variabel yang memberikan reaksi atau respons jika dihubungkan dengan variabel bebas (Sarwono, 2013:62). Nilai perusahaan digunakan sebagai variabel terikat (dependen) dimana Tobins'Q sebagai indikator perhitungannya. Sedangkan Market Value Added (MVA) digunakan sebagai variabel moderasinya.

Pengambilan sampel yang digunakan dalam penelitian ini adalah purposive sampling. Purposive sampling merupakan teknik Pengambilan sampel dilakukan sesuai dengan kriteria dan tujuan penelitian (Sekaran, 2006:136). Sampel ini ditentukan berdasarkan dengan syarat yang telah ditentukan sebagai berikut.

1. Merupakan perusahaan sektor transportasi dan infrastruktur yang terdaftar di Bursa Ekek Indonesia periode 2011-2015.

2. Perusahaan sektor transportasi dan infrastruktur yang tidak pernah delisting di Bursa Efek Indonesia periode 2011-2015.

3. Tersedia data keuangan yang lengkap dan telah diaudit pada periode 20112015. 
Sehingga dari 33 perusahaan yang memenuhi kriteria pertama, kemudian hanya ada tiga perusahaan yang memenuhi persyaratan kedua dan ketiga, diantara lain Samudera Indonesia, Mitra International Resources, dan Garuda Indonesia.

Penelitian ini menggunakan data kuantitatif, dimana data dinyatakan dengan angka-angka, menunjukan nilai terhadap besaran atau variabel yang diwakilinya. Teknik pengumpulan data yang digunakan dalam penelitian ini adalah teknik pengumpulan data sekunder dimana pencarian data dilakukan melalui teknik dokumentasi dengan mencatat atau menyalin data-data yang tertera dan bersumber dari idx.co.id. Data yang diperlukan dalam penelitian ini antara lain:

1. Laporan tahunan (annual report) yang diterbitkan oleh perusahaan sampel terpilih yang diakses dari idx.co.id.

2. Laporan keuangan perusahaan sampel terpilih utnuk periode 2011-2015.

Teknik pengumpulan data yang digunakan dalam penelitian ini adalah sebagai berikut:

1. Sumber data online yang dapat diakses dari internet.

2. Studi pustaka, pengumpulan data yang dlakukan yaitu dengan mempelajari hasil penelitian terdahulu yang mendukung penelitian yang sedang dilakukan.

Teknik analisis data yang digunakan dalam penelitian ini adalah dengan menggunakan teknik analisis regresi sederhana dan Moderated Regression Analysis (MRA. Untuk menguji pengaruh pengungkapan CSR dengan nilai perusahaan dengan menggunakan regresi sederhana. Sedangkan MRA atau uji interaksi untuk mengetahui apakah Market Value Added dapat memperkuat atau memperlemah hubungan antara pengungkapan CSR dengan nilai perusahan.

\section{Hasil dan Diskusi}

\section{Corporate Social Responsibility Diclosure Index}

Indeks CSR ini dapat diperoleh dengan cara menganalisis isi dari laporan tahunan perusahaan mengenai informasi CSR yang diungkapkan berdasarkan 79 item pengungkapan CSR. Untuk memperoleh skor indeks CSR dapat dilakukan check list dari daftar pernyataan yang berisi item-item pengungkapan CSR yang terdapat pada laporan tahunan dari setiap perusahaan yang dijadikan sampel. Setiap item yang diungkapkan diberikan angka 1 dan item yang tidak diungkapkan pada laporan tahunan perusahaan tersebut diberikan angka 0. Skor akhir indeks CSR diperoleh dengan cara menjumlahkan skor item yang diungkapkan oleh setiap perusahaan untuk memperoleh total skor yang kemudian dibagi dengan 79 item pengungkapan CSR.

Tabel 2. Skor Indeks CSR Perusahaan Sektor Transportasi dan Infrastruktur

\begin{tabular}{|c|l|r|r|r|r|r|}
\hline \multirow{2}{*}{ No } & \multirow{2}{*}{ Nama Perusahaan } & \multicolumn{5}{|c|}{ Indeks CSRD } \\
\cline { 3 - 7 } & & $\mathbf{2 0 1 1}$ & $\mathbf{2 0 1 2}$ & $\mathbf{2 0 1 3}$ & $\mathbf{2 0 1 4}$ & $\mathbf{2 0 1 5}$ \\
\hline 1 & Samudera Indonesia & 0.089 & 0.19 & 0.266 & 0.19 & 0.152 \\
\hline 2 & Mitra International Resources & 0.101 & 0.063 & 0.089 & 0.127 & 0.101 \\
\hline 3 & Garuda Indonesia & 0.266 & 0.215 & 0.291 & 0.215 & 0.266 \\
\hline RATA-RATA CSRDI & & & 0.17473 \\
\hline STANDAR DEVIASI & & 0.07703 \\
\hline CSRDI TERTINGGI & & 0.291 \\
\hline CSRDI TERENDAH & & 0.063 \\
\hline
\end{tabular}

Berdasarkan Tabel 2, rata-rata pengungkapan CSR pada perusahaan sektor transportasi dan infrastruktur sebesar 0.174. Indeks CSR tertinggi dimiliki oleh Garuda Indonesia pada tahun 2013 yaitu sebesar 0.291 atau berada di atas rata-rata, yang berarti bahwa perusahaan Garuda Indonesia memiliki komitmen penuh dalam mempertanggungjawabkan dampak operasinya tidak hanya memikirkan keuntungan jangka pendek tetapi mulai mengarah kepada investasi jangka panjang yang berkelanjutan. Sehingga perusahaan mendapatkan citra baik dari masyarakat 
yang nantinya akan meningkatkan keuntungan dari produk dan jasa yang perusahaan tawarkan. Sedangkan indeks CSR terendah terdapat pada perusahaan Mitra International Resources pada tahun 2012 sebesar 0.063 atau di bawah rata-rata, yang berarti perusahaan tidak berkomitmen dalam mempertanggungjawabkan dampak operasi seperti yang sudah ditetapkan.

Tren yang terjadi dari keseluruhan perusahaan memiliki indeks CSR berfluktuatif, tidak ada kenaikan atau penurunan yang terus menerus. Hal ini mengindikasikan bahwa adanya kesadaran perusahaan untuk terus mencoba dalam memperluas pengungkapan CSR yang dilakukan oleh perusahaan sehingga akan menciptakan citra baik dari masyarakat yang berkelanjutan. Standar deviasi dari pengungkapan CSR pada perusahaan sektor transportasi dan infrastruktur sebesar 0.077 $<1$, artinya bahwa pengungkapan CSR tidak bervariasi.

\section{Market Value Added (MVA)}

Market Value Added (MVA) dihitung dengan menggunakan nilai pasar ekuitas dikurangi dengan modal yang diinvestasikan. Setelah menghitung seluruh komponen yang diperlukan dalam perhitungan MVA, selanjutnya dapat diketahui nilai MVA dari setiap perusahaan.

Tabel 3 . Nilai MVA Perusahaan Sektor Transportasi dan Infrastruktur

\begin{tabular}{|c|c|c|c|c|c|c|}
\hline \multirow{2}{*}{$\mathrm{N}_{0}$} & \multirow{2}{*}{ Nama Perusahaan } & \multicolumn{5}{|c|}{ MVA (Jutaan Rupiah) } \\
\hline & & 2011 & 2012 & 2013 & 2014 & 2015 \\
\hline & Samudera Indonesia & 524,922 & 203,437 & $(87,871)$ & $1,847,936$ & 176,759 \\
\hline 2 & Mitra International Resources & 148,578 & $(7,979)$ & $(265,444)$ & $(297,132)$ & $(297,132)$ \\
\hline 3 & Garuda Indonesia & $(566,023)$ & $3,915,941$ & $(2,578,575)$ & $(1,670,874)$ & $(3,615,990)$ \\
\hline \multicolumn{6}{|c|}{ RATA-RATA } & $(171,296)$ \\
\hline \multicolumn{6}{|c|}{ STANDARDEVIASI } & $1,727,323.03$ \\
\hline \multicolumn{6}{|c|}{ MVA TERTINGGI } & $3,915,941$ \\
\hline \multicolumn{6}{|c|}{ MVA TERENDAH } & $(3,615,990)$ \\
\hline
\end{tabular}

Berdasarkan Tabel 3 di atas, nilai MVA tertinggi terdapat pada perusahaan Garuda Indonesia pada tahun 2012 sebesar Rp. 3.915.941,-, hal ini menggambarkan bahwa nilai MVA positif (nilai MVA > 1) artinya total market value Garuda Indonesia berada di atas modal yang diinvestasikan atau dapat juga menunjukan bahwa perusahaan berhasil memaksimalkan kekayaan pemegang saham perusahaan. Kemudian Garuda Indonesia mendapatkan nilai MVA negatif pada tahun-tahun berikutnya. Tidak hanya Garuda Indonesia, Samudera Indonesia dan Mitra International Resources pun mengalami hal yang sama, kedua perusahaan ini mendapatkan nilai MVA negatif. Mitra International Resources terus menerus mendapatkan nilai negatif sejak tahun 2012 hingga 2015, sedangkan Samudera Indonesia mengalami hal yang sama yang terjadi pada tahun 2013 yaitu sebesar Rp. 87.821,-. Setelah perolehan nilai-nilai tersebut, didapatkan rata-rata nilai MVA perusahaan sektor transportasi dan infrastruktur sebesar Rp. -171.296,-, hal tersebut mengindikasikan bahwa nilai MVA negatif (nilai MVA < 1) yang berarti nilai dari investasi yang dijalankan manajemen kurang dari modal yang diserahkan ke perusahaan oleh pasar modal.

\section{Nilai Perusahaan}

Nilai perusahaan dapat memberikan kemakmuran pemegang saham secara maksimum apabila harga saham terus meningkat. Semakin tinggi harga saham, maka semakin tinggi kemakmuran pemegang saham dan dapat dikatakan nilai perusahaannya juga baik.

Nilai perusahaan diproksikan dengan nilai Tobin's Q, nilai Tobin's Q diperoleh dari nilai pasar ekuitas ditambah dengan total utang kemudian dibagi dengan total aktiva. 
Tabel 4. Nilai Perusahaan Sektor Transportasi dan Infrastruktur

\begin{tabular}{|c|c|c|c|c|c|c|}
\hline \multirow{2}{*}{$\mathrm{N}_{0}$} & \multirow{2}{*}{ Nama Perusahaan } & \multicolumn{5}{|c|}{ Tobin's Q } \\
\hline & & 2011 & 2012 & 2013 & 2014 & 2015 \\
\hline 1 & Samudera Indonesia & 0.7 & 0.69 & 0.63 & 0.63 & 0.59 \\
\hline 2 & Mitra International Resources & 1.84 & 1.45 & 0.74 & 0.73 & 0.73 \\
\hline 3 & Garuda Indonesia & 1.18 & 1.17 & 0.94 & 1.08 & 1.03 \\
\hline \multicolumn{6}{|c|}{ RATA-RATA } & 0.942 \\
\hline \multicolumn{6}{|c|}{ STANDAR DEVIASI } & 0.35569248 \\
\hline \multicolumn{6}{|c|}{ TOBIN'S Q TERTINGGI } & 1.84 \\
\hline \multicolumn{6}{|c|}{\begin{tabular}{|l|} 
TOBIN'S Q TERENDAH \\
\end{tabular}} & 0.59 \\
\hline
\end{tabular}

Berdasarkan Tabel 4 di atas, dapat dilihat bahwa rata-rata nilai perusahaan yang diproksikan dengan Tobin's Q pada perusahaan sektor transportasi dan infrastruktur sebesar 0,942. Dan nilai perusahaan terendah dimiliki oleh perusahaan Samudera Indonesia pada tahun 2015 yaitu 0,59. Hal tersebut mengidikasikan bahwa nilai Tobin's $\mathrm{Q}<1$ yang artinya investasi dalam aset tidaklah menarik karena memiliki potensi pertumbuhan yang rendah sehingga perusahaan dinilai lebih rendah oleh pasar keuangan. Sedangkan nilai perusahan tertinggi sebesar 1.84 yang dimiliki oleh perusahaan Mitra International Resources pada tahun 2011 mengindikasikan bahwa nilai Tobin's $Q>1$ yang artinya investasi dalam asset memberikan keuntungan yang lebih tinggi daripada modal yang dikeluarkan, sehingga akan merangsang investasi baru. Tren nilai perusahaan sangat variatif dan berfluktuatif. Standar deviasi yang dihasilkan yaitu sebesar 0,35 < 1 maka menggambarkan bahwa nilai perusahaan pada perusahaan sektor transportasi dan infrastruktur tidak bervariasi.

\section{Uji Hipotesis Pengaruh Pengungkapann CSR Terhadap Nilai Perusahaan}

Dalam penelitian dilakukan pengujian regresi sederhana untuk mengetahui hubungan antara variabel independen Corporate Social Responsibility dengan nilai perusahaan yang diproksikan dengan Tobin's Q sebagai variabel dependen secara parsial maupun simultan. Berdasarkan penelitian yang telah dilakukan, diperoleh nilai koefisien determinasi $\left(R^{2}\right)$ sebesar 0.013 atau $1,3 \%$ yang artinya $1,3 \%$ nilai perusahaan dipengaruhi oleh pengungkapan CSR, sisanya yaitu $98.7 \%$ dipengaruhi oleh variabel lain yang tidak diungkapkan pada penelitian ini dan diperoleh F hitung sebesar 0.196. Dengan menggunakan tingkat kepercayaan sebesar $\alpha=0.05$ dan nilai signifikansinya sebesar 0.897. dalam uji $\mathrm{F}$ ini diperlukan mencari $\mathrm{F}$ tabel untuk membandingkan dengan $\mathrm{F}$ hitung. Pada tingkat signifikansi 0.05 dengan derajat kebebasan df $1=3$ diperoleh dari jumlah variabel dikurangi 1 , dan df $2=$ 12 diperoleh dari jumlah data sampel dikurangi dengan variabel bebas dikurangi 1. Sehingga hasil F tabel sebesar 3.490.

Dengan perolehan $\mathrm{F}$ hitung $<\mathrm{F}$ tabel dan signifikansinya $0.897>0.05$ yang berarti bahwa variabel independen yang dimasukan pada penelitian ini yang meliputi pengungkapan CSR, MVA dan interaksi antara CSR dan MVA secara bersama-sama tidak berpengaruh secara signifikan terhadap nilai perusahaan. Diperoleh thitung dari variabel independen Corporate Social Responsibility (CSR) sebesar -0.421 dan nilai signifikansi sebesar $0.681>0.05$ yang berarti $H_{0}$ diterima. Jika ditinjau dari perhitungan $\mathrm{t}$ tabel, dapat dilihat pada tabel statistik $\mathrm{t}$ pada signifikansi $0.05 / 2=0.025$ dengan derajat kebebasan $\mathrm{df}=$ jumlah data sampel dikurangi 2 atau $15-2=13$, sehingga perolehan $\mathrm{t}$ tabel sebesar 2.160. Maka $\mathrm{t}$ hitung $>\mathrm{t}$ tabel $(-0.421<2.160)$ yang berarti $H_{0}$ diterima dan dengan signifikansi $0.681>0.05$ mengindikasikan variabel pengungkapan CSR tidak berpengaruh signifikan terhadap nilai perusahaan yang diproksikan dengan Tobin's Q dan perolehan koefisien regresi dari pengungkapan CSR sebesar -0.080 yang berarti bahwa setiap penambahan satu variabel CSR akan menurunkan nilai perusahaan sebesar 0.080. Dengan begitu, pengungkapan CSR yang dilakukan pada perusahaan sektor transportasi dan infrastruktur periode tahun 2011 sampai 
dengan tahun 2015 tidak dapat meningkatkan nilai perusahaannya.

\section{Market Value Added Sebagai \\ Pemoderasi Hubungan PEngungkapan Corporate Social Responsibility Dengan Nilai Perusahaan}

Dalam penelitian ini dilakukan moderate regression analysis untuk mengetahui ada atau tidaknya pemoderasi yang diproksikan dengan Market Value Added (MVA) terhadap hubungan Corporate Social Responsibility (CSR) dengan nilai perusahaan. Berdasarkan perhitungan dalam penelitian ini, interaksi antara Corporate Social Responsibility (CSR) dengan Market Value Added (MVA) memperoleh nilai signifikansi sebesar $0.602>0.05$, yang artinya $H_{0}$ diterima. Sehingga dapat disimpulkan bahwa interaksi CSR dengan MVA tidak mampu memoderasi hubungan antara CSR dengan nilai perusahaan. Dalam hal ini MVA tidak dapat memperkuat atau memperlemah pengungkapan CSR karena kinerja pasar pada pasar keuangan sudah efisien, sehingga semua informasi sudah langsung tercermin pada harga saham perusahaan. Jadi upaya apapun yang dilakukan perusahaan untuk mensejahterakan para pemegang sahamnya tidak dapat mempengaruhi hubungan pengungkapan CSR dengan nilai perusahaan.

\section{Kesimpulan, Keterbatasan, dan Saran}

\section{Kesimpulan}

Pengungkapan CSR tidak berpengaruh signifikan terhadap nilai perusahaan. Hal ini dibuktikan dengan uji regresi sederhana yang memperoleh nilai signifikansi $0.681>0.5$ dan $\mathrm{t}$ hitung $>\mathrm{t}$ tabel yaitu $-0.421<2.160$ yang berarti $H_{0}$ diterima. Ini mengindikasikan bahwa tingginya tingkat tanggung jawab sosial (CSR) tidak akan membuat perusahaan memiliki citra positif dari masyarakat khususnya di kalangan bisnis, sehingga perusahaan tidak akan mendapatkan respon dari masyarakat akan ekstensinya di dunia bisnis yang nantinya akan meningkatkan nilai perusahaan. Market Value Added (MVA) tidak mampu memoderasi hubungan pengungkapan CSR terhadap nilai perusahaan. Hal ini dibuktikan dengan uji moderate regression analysis yang memperoleh nilai signifikanti sebesar $0.602>0.05$. Pengungkapan CSR tidak dapat meningkatkan nilai perusahaan pada saat MVA perusahaan tinggi, dan sebaliknya CSR juga tidak dapat menurunkan nilai perusahaan pada saat MVA perusahaan rendah.

\section{Keterbatasan dan Saran}

Perusahaan sektor transportasi dan infrastruktur wajib memperhatikan lagi tanggungjawab sosialnya serta harus mencantumkan secara lengkap pada annual report sesuai dengan kegiatan tanggung jawab sosial yang telah dilaksanakan dan meningkatkan publikasi kegiatan CSR perusahaan. Selanjutnya perusahaan sektor transportasi dan infrastruktur juga harus meningkatkan kinerja manajemen dalam mengelola modal yang telah dipercayakan investor kepada perusahaan sehingga akan tercipta kekayaan bagi pemegang saham. Peneliti selanjutnya hendaknya melakukan penelitian dengan jumlah sampel yang lebih besar dan melakukan penelitian dengan periode yang lebih panjang agar kesimpulan yang dihasilkan memiliki cakupan yang lebih luas. Di samping itu, nilai $\mathrm{R}$ square pada penelitian ini masih relatif kecil yaitu $1,3 \%$ yang menunjukan bahwa terdapat variabel lain yaitu $98,7 \%$ yang mempengaruhi nilai perusahaan. Dengan demikian, penelitian selanjutnya dapat menambah atau menggunakan variabel lainnya untuk mengetahui lebih lanjut variabel apa saja yang mempengaruhi nilai perusahaan. 


\section{DAFTAR PUSTAKA}

Elkington, J. (1997). Cannibals with forks.

The triple bottom line of 21 st century.

Eforis, C. dan Suryaningsih, R. (2011). Pengaruh Pengungkapan CSR Pada Nilai Perusahaan, 3(2), 1-19. Ultima Accounting.

Freeman, R. E. (1984). Strategic Management: A Stakeholder Approach, Boston, Pitman.

Hadi, N. (2011). Corporate Social Responsibility. Yogyakarta: Graha Ilmu.

Harsanti, P. (2011). Corporate Social Responsibility dan Teori Legitimasi. Jurnal Staf Pengajar Pada Fakultas Ekonomi. Universitas Maria Kudus. Juni: 1-7

Sarwono, J. (2013). Statistik Multivariat Aplikasi untuk Riset Skripsi. Yogyakarta: Andi.

Sekaran, U. (2006). Metodologi Penelitian untuk Bisnis Edisi 4. Jakarta: Salemba Empat.

https://ejournals.umn.ac.id/index.php/Ak un/article/view/432

http://eprints.umk.ac.id/3128/ 